\title{
Biochemical changes during the initial stages of industrial lead exposure
}

\author{
G. I. BENSON ${ }^{1}$, W. H. S. GEORGE ${ }^{2}$, M. H. LITCHFIELD ${ }^{3}$, and \\ D. J. SEABORN ${ }^{3}$ \\ I.C.I. Organics Division, Derby Works, Derby ${ }^{1}$, the Department of Pathology, Derby City \\ Hospital, Derby ${ }^{2}$, and I.C.I. Central Toxicology Laboratory, Alderley Park, Cheshire ${ }^{3}$.
}

\begin{abstract}
Benson, G. I., George, W. H. S., Litchfield, M. H., and Seaborn, D. J. (1976). British Journal of Industrial Medicine, 33, 29-35. Biochemical changes during the initial stages of industrial lead exposure. Biochemical measurements were carried out on 20 workers entering employment in a lead industry. Blood lead ( $\mathrm{Pb}-\mathrm{B})$, urinary $\delta$-aminolevulinic acid (ALA), and coproporphyrin (CP) levels were determined before entry and then at approximately weekly intervals for the first 12 weeks of employment. Levels of blood lead began to increase in all men within one week rising from an average pre-employment figure of about $1 \cdot 1 \mu \mathrm{mol} / 1(22 \mu \mathrm{g} / 100 \mathrm{ml})$ to a value of about $2.9 \mu \mathrm{mol} / 1(60 \mu \mathrm{g} / 100 \mathrm{ml})$ at three weeks. Subsequently there was only a small increase and $\mathrm{Pb}-\mathrm{B}$ values levelled for the rest of the period. There was no increase in urinary ALA and CP in most subjects during the first two weeks; thereafter there was a variable pattern of excretion although three main groups of response could be discerned. Urinary ALA and CP changes related well to each other but their correlation with the characteristic increase in $\mathrm{Pb}-\mathrm{B}$ fell into three categories of relationship. The major finding of the study was the very contrasting response shown by some individuals. This emphasized the need for a reasonably comprehensive biochemical screen during the early stages of employment in the lead industry in order to assess the individual biological response of a new employee to this environment. The measurement of $\mathrm{Pb}-\mathrm{B}$ and urinary $\mathrm{CP}$ or ALA was advocated for this purpose.
\end{abstract}

The health monitoring of personnel working in the lead industry is well established and is carried out by clinical, biochemical, and haematological examinations. The usefulness of biochemical monitoring has been assessed by several investigators and includes the measurement of blood lead $(\mathrm{Pb}-\mathrm{B})$, urinary lead, coproporphyrin $(\mathrm{CP})$, and $\delta$-aminolevulinic acid (ALA). In particular, blood lead has been shown to be an indicator of absorption (Haeger-Aronsen, 1971; Waldron, 1971; Davies, 1972), while urinary CP and ALA are reliable indicators of effect (Gibson, Mackenzie, and Goldberg, 1968; Haeger-Aronsen, 1971). The attempts to find correlations among these biochemical parameters and other indices of effect have produced differing results ranging from significant correlation between the parameters of absorp-

Requests for reprints to MHL tion and effect (Cramér and Selander, 1965; Williams, King, and Walford, 1969; Wada et al., 1973) to no positive relationship (Gibson et al., 1968). The overall view, however, is that some combination of these measurements provides a useful screen for monitoring the exposure of workers in the lead industry.

Most surveys on the efficacy of biochemical monitoring, apart from that of Tola et al. (1973) for example, have been carried out on an established work population including employees with an appreciable history of lead exposure. It has also been a feature of these surveys to base the findings on population means and to use these results for the assessment of the usefulness of various tests. It is well known, however, that pharmacological responses to a toxic insult can vary markedly between individuals, particularly during the early 
stages of an effect. It was with these considerations in mind that the opportunity was taken to monitor workers during the first few weeks of their employment in a lead pigment factory. The results of this study, using blood lead and urinary CP and ALA measurements as indicators of exposure, are reported here.

\section{Material and methods}

\section{Subjects and exposure}

The survey was conducted on 20 men entering employment in lead pigment manufacture during a period of about 16 months. The men examined were aged between 25 and 50 years and all except two had had no previous history of industrial lead exposure. The place of employment was a conventional lead pigment manufacturing factory with background air concentrations around the major processes of $0.05-0.15 \mathrm{mg} \mathrm{Pb} / \mathrm{m}^{3}$ as shown by sampling surveys. Personal sampling on these surveys showed that, occasionally, levels of up to $5 \mathrm{mg} \mathrm{Pb} / \mathrm{m}^{3}$ existed. In such circumstances the men wore protective clothing in the form of an overall, gloves, and a face mask. During their first 12 weeks of employment the men were engaged on a variety of tasks representing a broad spectrum of the factory's activities in order to gain job experience.

\section{Monitoring procedures}

Each man was medically examined upon entry and an initial blood sample and urine sample were taken for analysis. A sample of blood and a sample of urine were taken from each man between 10.00 and 12.00 hours daily during the first week and, subsequently, as far as circumstances permitted, at weekly intervals during the first 12 weeks of employment. Every week, each subject was interviewed by the Works Medical Officer for an assessment of his clinical condition.

Blood ( $5 \mathrm{ml}$ ) was taken by venepuncture for the determination of haemoglobin and lead content. Urine specimens were divided into three: one sample was adjusted to below $\mathrm{pH} 7.0$ with acetic acid for ALA determination, the second was adjusted to $\mathrm{pH}$ 6.0-9.5 with solid sodium carbonate for CP determination, and the third was used for immediate semi-quantitative CP estimation. If a delay in urine analysis was unavoidable the sample was stored at a temperature of $4^{\circ} \mathrm{C}$ until required. All samples were taken with great care to avoid contamination.

The number of hours worked by the total workforce in the factory was recorded each week, and this was used in conjunction with the tonnage of pigment produced and the number of men involved to give a weekly production index (PI) as an indicator of overall exposure.

\section{Analytical methods}

Blood haemoglobin was determined by a standard colorimetric method (Dacie, 1956), and blood lead by the Delves cup procedure (Delves, 1970), using a Perkin Elmer model 107 atomic absorption spectrophotometer. Urinary ALA and CP were determined by the methods of Davis and Andleman (1967) and Henry (1964), respectively. Urinary coproporphyrin was also measured using a semi-quantitative method in order to compare it with the above quantitative laboratory procedure. To $10 \mathrm{ml}$ urine were added $2 \mathrm{ml} 8 \% \mathrm{v} / \mathrm{v}$ acetic acid in ether and after shaking thoroughly the mixture was allowed to separate for exactly 10 minutes. The fluorescence of the supernatant layer under ultraviolet light was estimated by eye and graded for coproporphyrin content according to a colour index from normal (no fluorescence) to +++ (a very strong pink).

\section{Results}

None of the men showed overt clinical signs indicative of lead poisoning on the evidence of repeated interviews over the 12-week period. Haemoglobin values remained within a normal range (13-16 g/dl) during the period and no individual showed significant changes in this respect. Most of the men entered employment during a period of steady production which was maintained at the characteristically uniform level of approximately $150 \mathrm{PI}$. In a few cases however, there were marked fluctuations in PI soon after a man began employment due to a summer or Christmas break in production.

The results for the 20 men are shown in Table 1 . Figs 1-3 illustrate graphically typical examples of responses found during the first 12 weeks of employment. It was not possible to obtain weekly figures for each man during the whole of his 12-week period of surveillance, but sufficient data are available to comment on the changes taking place with the above parameters.

\section{Blood lead}

From a statistical evaluation of the data, the best fitting simple relationship between blood lead and exposure time was found to be:

$\mathrm{Pb}-\mathrm{B}(\mu \mathrm{mol} / \mathrm{l})=3.3-2.2 \mathrm{exp}$. [ -0.6 (weeks)] This curve, with a separate constant term for each subject, accounted for $78 \%$ of the variation in the blood lead data. Fig. 4 shows the curve based on the above equation for the average of the 20 subjects and for the two subjects with the most extreme values. The initial blood lead value for each new entrant was approximately $1 \cdot 1 \mu \mathrm{mol} / 1(22 \mu \mathrm{g} / 100 \mathrm{ml})$ apart from one man with a previous history of lead exposure whose value was $2 \cdot 2 \mu \mathrm{mol} / 1(45 \mu \mathrm{g} / 100 \mathrm{ml})$ (Subject 6). Within one week of entering employment levels of $\mathrm{Pb}-\mathrm{B}$ began to rise significantly in all cases. In most cases this rise continued for about three weeks, reaching a value in the region of 2.9 $\mu \mathrm{mol} / 1 \mathrm{l}(60 \mu \mathrm{g} / 100 \mathrm{ml})$. Subsequently, Pb-B levelled to an average figure of about 2:4-3.9 $\mu \mathrm{mol} / 1$ (50-80 $\mu \mathrm{g} / 100 \mathrm{ml}$ ) although a few men showed transitory rises above $3.9 \mu \mathrm{mol} / 1(80 \mu \mathrm{g} / 100 \mathrm{ml})$ during the 12-week period.

\section{Urinary CP and ALA}

The initial CP value for each new entrant was approximately $0 \cdot 12 \mu \mathrm{mol} / 1(0 \cdot 12 \pm 0.06)(8 \mu \mathrm{g} / 100 \mathrm{ml}$; 
TABLE 1

Blood Lead (Pb-B) and Urinary Ala and Coproporphyrin (CP) Values ( $\mu \mathrm{mol} / \mathrm{l}) \mathrm{IN}$ Men During the First 12 Weeks of Industrial Lead Exposure (PI = Production Index)

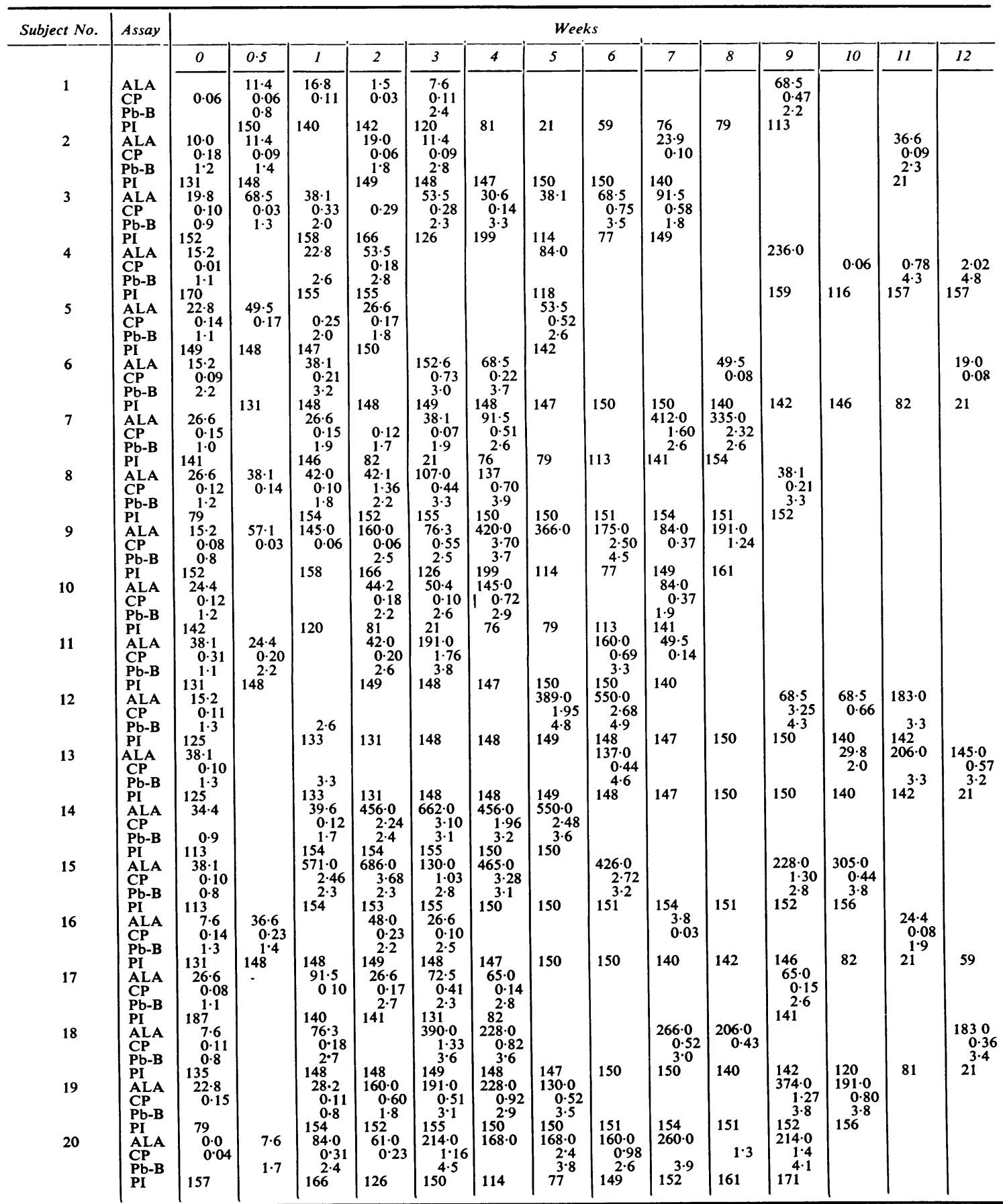

Conversion factors to: $\mu \mathrm{g} / 100 \mathrm{ml} \mathrm{Pb}-\mathrm{B}=20 \cdot 7 ; \mu \mathrm{g} / 100 \mathrm{ml} \mathrm{CP}=65.5 ; \mathrm{mg} / 100 \mathrm{ml} \mathrm{ALA}=0.0131$. 


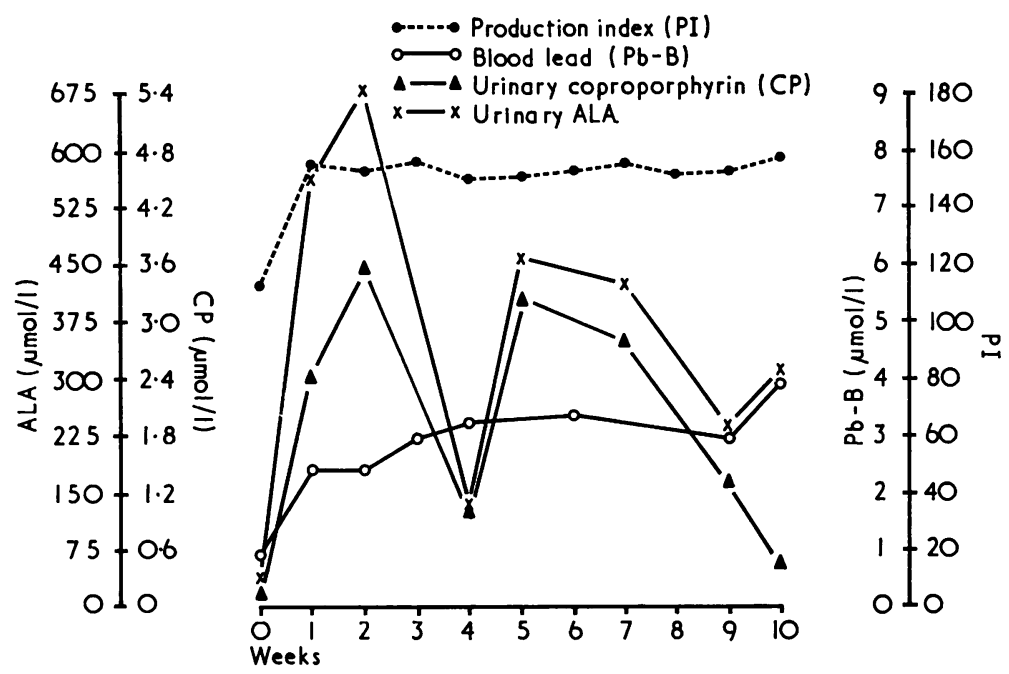

FIG. 1. Blood lead (Pb-B), urinary CP and ALA, and PI, Subject No. 15.

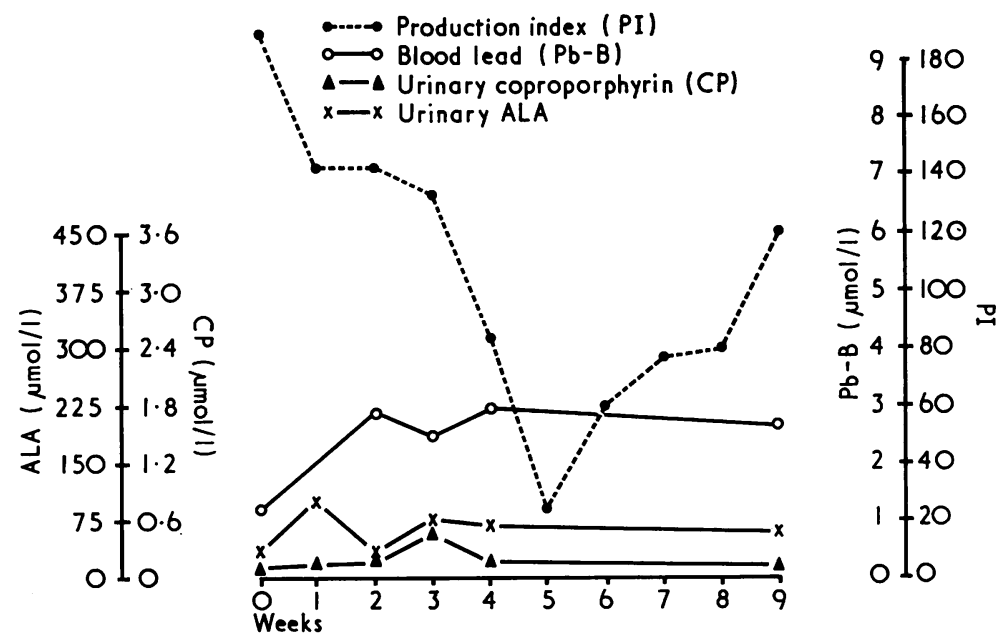

FIG. 2. Blood lead (Pb-B), urinary CP and ALA, and PI, Subject No. 17. 


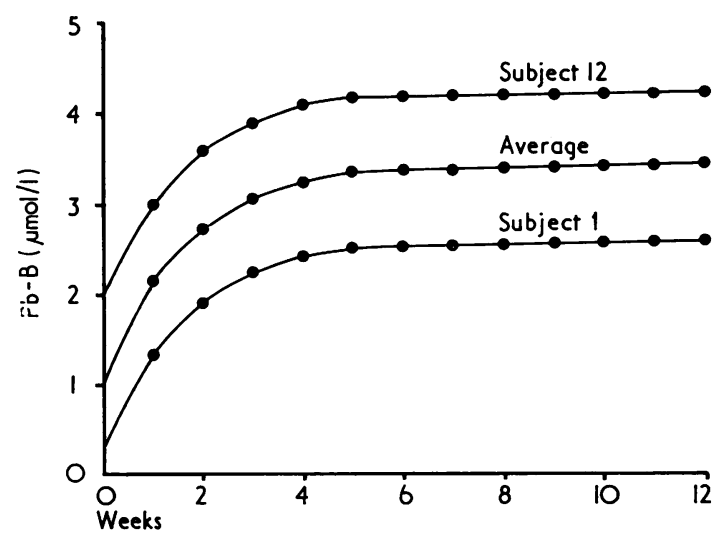

FIG. 4. The best fitting simple relationship between $\mathrm{Pb}-\mathrm{B}$ and time for the average of 20 subjects and for the two extreme values.

$7 \cdot 8 \pm 4 \cdot 1)$ and the ALA was about $23 \mu \mathrm{mol} / \mathrm{l}(23 \pm$ 9) $(0.3 \mathrm{mg} / 100 \mathrm{ml} ; 0.28 \pm 0.12)$. These two parameters can be considered jointly since their pattern of response was similar. The correlation coefficient for the CP and ALA values was $\mathbf{0 . 8 4}$ and the ratio CP:ALA was uncorrelated with exposure time, while the variation in this ratio between subjects was not significant. Figs 1-3 show that the individual variation after exposure to lead was considerably more variable than the response for $\mathrm{Pb}-\mathrm{B}$.

The variations about subject mean values are set out in Table 2 and demonstrate low values for both parameters for most subjects during the first two weeks followed by a rise to higher levels which was maintained for the remainder of the study period.
Not all subjects followed this average pattern, however, and it is easier to portray the alterations in terms of three response patterns. One group of men showed rises in excretion during the third and fourth weeks followed by an increased, but variable response, during the rest of the period (Subjects 6-11, 18-20). A second group showed negligible changes during the period (Subjects 1, 2, 16, 17), while two subjects (14 and 15) showed an exaggerated response for the two parameters within two weeks of entry. One of these subjects (no. 14) had a history of previous lead exposure although his $\mathrm{Pb}-\mathrm{B}$ and ALA were normal on entry.

\section{Interrelationships}

Blood lead changes appear to follow a consistent pattern in all individuals despite the differences in the PI to which different men are exposed. The CP and ALA show a greater tendency to follow changes in the PI but there are several cases where there are marked variations during periods of steady production (for example, Subject 15). The CP and ALA generally relate well to one another as already described above and, similarly, their relationship with changes in $\mathrm{Pb}-\mathrm{B}$ can be placed in three categories. First, where all three parameters show reasonable correlation during the 12-week period (Subjects 7-12, 18-20), secondly where there is the characteristic response by $\mathrm{Pb}-\mathrm{B}$ but a subdued response by $\mathrm{CP}$ and ALA (Subjects 1-3, 5, 16, 17), and thirdly where there is the characteristic increase in $\mathrm{Pb}-\mathrm{B}$ but an exaggerated response by CP and ALA (Subjects 14, 15).

\section{Correlation between CP methods}

During the study the opportunity was taken to com-

TABLE 2

Deviations from Subject Mean Values for Urinary CP and AlA

\begin{tabular}{|c|c|c|c|c|c|c|c|c|}
\hline \multirow{3}{*}{ Weeks } & \multicolumn{4}{|c|}{ Coproporphyrin } & \multicolumn{4}{|c|}{$A L A$} \\
\hline & \multirow{2}{*}{$\begin{array}{l}\text { Observations } \\
\text { (No.) }\end{array}$} & \multicolumn{3}{|c|}{ Deviation } & \multirow{2}{*}{$\begin{array}{c}\text { Observations } \\
\text { (No.) }\end{array}$} & \multicolumn{3}{|c|}{ Deviation } \\
\hline & & Positive & Negative & $\begin{array}{l}\text { Average } \\
(\mu \mathrm{mol} / \mathrm{l})\end{array}$ & & Positive & Negative & $\begin{array}{l}\text { Average } \\
(\mu \mathrm{mol} / \mathrm{l})\end{array}$ \\
\hline $\begin{array}{r}0 \\
0.5 \\
1.0 \\
2.0 \\
3.0 \\
4.0 \\
5.0 \\
6.0 \\
7.0 \\
8.0 \\
9.0 \\
10.0 \\
11.0 \\
12.0\end{array}$ & $\begin{array}{r}19 \\
8 \\
13 \\
16 \\
16 \\
11 \\
4 \\
7 \\
8 \\
5 \\
7 \\
5 \\
3 \\
4\end{array}$ & $\begin{array}{l}2 \\
1 \\
2 \\
5 \\
7 \\
6 \\
3 \\
6 \\
3 \\
3 \\
4 \\
2 \\
1 \\
2\end{array}$ & $\begin{array}{r}17 \\
7 \\
11 \\
11 \\
9 \\
5 \\
1 \\
1 \\
5 \\
2 \\
3 \\
3 \\
2 \\
2\end{array}$ & $\begin{array}{r}-0.47 \\
-0.24 \\
-0.37 \\
0.00 \\
0.12 \\
0.44 \\
0.23 \\
0.55 \\
0.00 \\
0.41 \\
0.32 \\
-0.34 \\
0.03 \\
0.29\end{array}$ & $\begin{array}{r}19 \\
9 \\
13 \\
14 \\
16 \\
12 \\
8 \\
7 \\
9 \\
4 \\
8 \\
4 \\
4 \\
3\end{array}$ & $\begin{array}{r}0 \\
3 \\
2 \\
4 \\
10 \\
10 \\
6 \\
7 \\
6 \\
3 \\
4 \\
1 \\
3 \\
1\end{array}$ & $\begin{array}{r}19 \\
6 \\
11 \\
10 \\
6 \\
2 \\
2 \\
0 \\
3 \\
1 \\
4 \\
3 \\
1 \\
2\end{array}$ & $\begin{array}{r}107 \\
-\quad 30 \\
-\quad 53 \\
8 \\
23 \\
53 \\
69 \\
76 \\
46 \\
53 \\
23 \\
-\quad 61 \\
-\quad 15 \\
-\quad 8\end{array}$ \\
\hline
\end{tabular}


pare the results of the quantitative laboratory method for CP with those of the semi-quantitative screening procedure. The correlation of results is shown graphically in Fig. 5. This graph indicates the ranges for the semi-quantitative method in terms of $\mu \mathrm{mol} / 1 \mathrm{CP}$ to be: normal (0-0.15), trace (0.15-0.45), $+(0 \cdot 45-0 \cdot 75),++(0 \cdot 75-2 \cdot 25)$, and $+++(>2 \cdot 25)$.

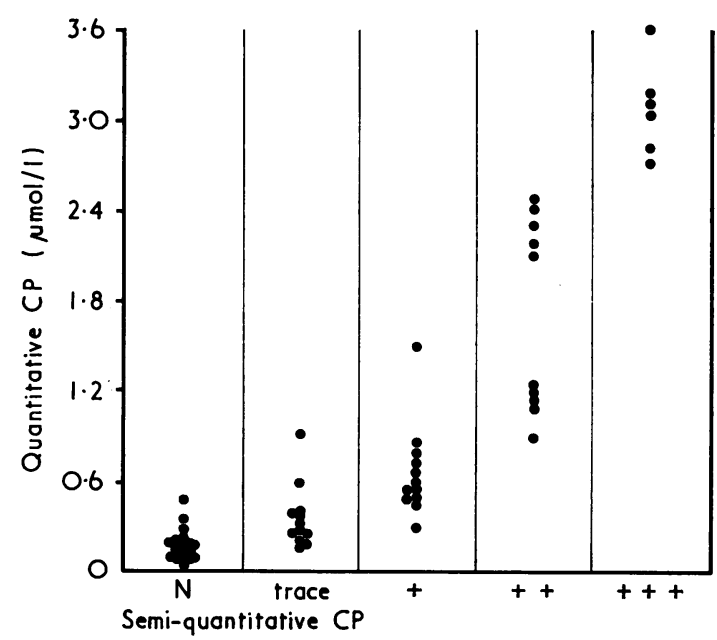

FIG. 5. Correlation between quantitative and semiquantitative urinary CP methods.

\section{Discussion}

The results of the survey of employees entering a lead industry for the first time show that a variety of responses occur in terms of $\mathrm{Pb}-\mathrm{B}$ and urinary $\mathrm{CP}$ and ALA changes. In all cases the $\mathrm{Pb}-\mathrm{B}$ increases follow a predictable pattern varying only in the magnitude of the rise which in itself is not too diverse between individuals. This time course of $\mathrm{Pb}-\mathrm{B}$ changes is apparently not affected by the amount of production during the initial 12-week periods nor by any sudden changes in production. This is not too surprising for two reasons. First, lead absorption must depend upon the type of work an individual is undertaking and by the personal intake of contaminated air. Secondly, blood lead concentrations probably do not alter rapidly once equilibrium has been set up between body fluids and tissues. It appears from the results that a level for $\mathrm{Pb}-\mathrm{B}$ is in existence within two or three weeks of entry indicating the establishment of the equilibrium within a relatively short period of time.

The results for urinary CP and ALA show a less predictable course of events than for $\mathrm{Pb}-\mathrm{B}$. These range from very marked increases within two weeks of entry for two individuals to little or no response for others although the $\mathrm{Pb}-\mathrm{B}$ concentrations in both cases are similar. There is, however, some uniformity in the pattern of changes to be discerned from the results. In many cases there is at least a two-week delay before significant changes take place and it is usual for the $\mathrm{Pb}-\mathrm{B}$ level to be above approximately $2.4 \mu \mathrm{mol} / 1(50 \mu \mathrm{g} / 100 \mathrm{ml})$ before a change in CP and ALA occurs, both observations being similar to those recognized by Tola et al. (1973). Although the time course for the two urinary parameters tends to be variable even during steady production these parameters are more responsive than $\mathrm{Pb}-\mathrm{B}$ to changes in production. In nearly all cases the results for urinary CP and ALA follow each other closely in accord with the degree of correlation shown for these two parameters by other investigators (Gibson $e$ t al., 1968; Williams et al., 1969; Haeger-Aronsen, 1971; Waldron, 1971). There are instances during the study where one measurement differs markedly from the other at any one time which, in isolation from the other serial results, may not give a valid picture of response.

The merits of screening lead workers using one or more of the recognized biochemical determinations have been discussed widely in the literature. Each test has its advocates, urinary $\mathbf{C P}$, for example, being recommended by Waldron (1971), urinary ALA by Haeger-Aronsen (1971), and the combination of $\mathrm{Pb}-\mathrm{B}$ and urinary ALA by Wada et al. (1973). These recommendations and those of most other investigators have been based upon studies of men well established in a lead industry and with several years of service. In the context of the screening of workers during their first few weeks of industrial lead exposure, it would appear that a combination of the above methods is required to establish the suitability of individuals for working in such an environment. The $\mathrm{Pb}-\mathrm{B}$ determinations rapidly establish the degree of lead uptake due to exposure while urinary CP and ALA demonstrate the individual metabolic response. There appears to be good evidence for using only one of the urinary parameters in the screen since their excretions follow one another closely. On the grounds of general acceptability, economy, and simplicity the CP test is favoured and, if necessary, analysis by a semi-quantitative method can be effective. Once a subject has worked in an industrial environment for some time then different considerations for monitoring may apply. In this situation it would seem that $\mathrm{Pb}-\mathrm{B}$ measurements are not such a useful index of absorption once a body equilibrium has been established, unless conditions worsen very rapidly. For the routine monitoring of a workforce in an established working routine it is sufficient probably to measure only urinary coproporphyrins on a regular basis (King and Thompson, 1961; Waldron, 1971). However, if it is suspected that an individual has been excessively exposed then more comprehensive screening is required. 
Regardless of which screen is selected for a population of workers it is essential to be aware of the very contrasting effects shown by some individuals in that group. This is illustrated vividly in the present study where two subjects ( 6 and 14 ) with previous employment in the industry showed contrasting responses when re-engaged. Although in both cases absorption indicated by $\mathrm{Pb}-\mathrm{B}$ results was shown to be similar, urinary $\mathrm{CP}$ and ALA excretion increased very markedly for Subject 14 necessitating his withdrawal from the work, while the other subject showed urinary values within normally accepted limits during the 12-week period.

It may be concluded that it is important to establish individual responses early in an exposure although it may be sufficient to monitor less comprehensively once a routine has been established.

The authors thank Dr. G. M. Paddle of the Imperial Chemical Industries Central Medical Unit, for valuable advice on statistical interpretation.

\section{References}

Cramér, K. and Selander, S. (1965). Studies in lead poisoning. Comparison between different laboratory tests. British Journal of Industrial Medicine, 22, 311314.

Dacie, J. V. (1956). Practical Haematology. Churchill, London.

Davies, M. H. (1972). The monitoring and control of industrial exposure to lead. Proceedings, International Symposium Environmental Health Aspects of Lead. Commission of the European Communities, Amsterdam, 2-6 October 1972, pp. 869-875.

Davis, J. R. and Andelman, S. L. (1967). Urinary deltaaminolevulinic acid (ALA) levels in lead poisoning: a modified method for the rapid determination of urinary delta-aminolevulinic acid using disposable ion-exchange chromatography columns. Archives of Environmental Health, 15, 53-59.

Delves, H. T. (1970). A micro-sampling method for the rapid determination of lead in blood by atomicabsorption spectrophotometry. Analyst (London), 95, 431-438.

Gibson, S. L. M., Mackenzie, J. C., and Goldberg, A. (1968). The diagnosis of industrial lead poisoning. British Journal of Industrial Medicine, 25, 40-51.

Haeger-Aronsen, B. (1971) An assessment of the laboratory tests used to monitor the exposure of lead workers. British Journal of Industrial Medicine, 28, 52-58.

Henry, R. J. (1964). Clinical Chemistry, Principles and Technics. Harper and Row, New York.

King, E. and Thompson, A. R. (1961). The measurement of lead absorption in industry. Annals of Occupational Hygiene, 3, 247-263.

Tola, S., Hernberg, S., Asp, S., and Nikkanen, J. (1973). Parameters indicative of absorption and biological effect in new lead exposure: a prospective study. British Journal of Industrial Medicine, 30, 134-141.

Wada, O., Yano, Y., Ono, T., and Toyokawa, K. (1973). The diagnosis of different degrees of lead absorption: in special references to choice and evaluation of various parameters indicative of an increased lead absorption. Industrial Health, 11, 55-67.

Waldron, H. A. (1971). Correlation between some parameters of lead absorption and lead intoxication. British Journal of Industrial Medicine, 28, 195-199.

Williams, M. K., King, E., and Walford, J. (1969). An investigation of lead absorption in an electric accumulator factory with the use of personal samplers. British Journal of Industrial Medicine, 26, 202-216.

Received for publication 12 February 1975. Accepted for publication 14 March 1975. 